\title{
Güney Doğu Karadeniz Kıyıları Pigmente Dayalı Fitoplankton Boy Gruplarının Dağılımı
}

\author{
Ertuğrul AĞIRBAŞ ${ }^{1 *}$, Pınar TÜRKMEN ${ }^{2}$ \\ ${ }^{1}$ Recep Tayyip Erdoğan Üniversitesi, Su Ürünleri Fakültesi, Temel Bilimler Bölümü, 53100 Rize, Türkiye \\ ${ }^{2}$ Recep Tayyip Erdoğan Üniversitesi, Fen Bilimleri Enstitüsü, Su Ürünleri Anabilim Dal, 53100 Rize, Türkiye \\ "Sorumlu Yazar/Corresponding Author \\ E-mail: ertugrul.agirbas@erdogan.edu.tr \\ Araștırma makalesi/Research article \\ Orcid ID: 0000-0001-7987-9668 \\ Geliş tarihi/Received:16.04.2021 \\ Kabul tarihi/Accepted:09.06.2021
}

\section{ÖZET}

Bu çalışmada Güney Doğu Karadeniz kıyılarında (Artvin-Giresun) belirteç pigment kompozisyonu ve pigmente dayalı fitoplankton boy gruplarının alansal ve zamansal dağılımı Kasım 2014-Ağustos 2015 dönemleri arasında araştırılmıştır. Çalışma kapsamında 12 farklı istasyonda yüzeyden itibaren $10 \mathrm{~m}$ aralıklarla $40 \mathrm{~m}$ derinliğe kadar mevsimsel örneklemeler gerçekleştirilmiştir. HPLC analizleri sonucunda fitoplankton boy gruplarının toplam fitoplankton biyokütlesine yaptığı katkı pikoplankton, nanoplankton ve mikroplankton için sırasıyla \%1-71, \%180 ve \%8-93 arasında değişim göstermiştir. Mevsimsel olarak bir değerlendirme yapıldığında kış ve ilkbahar döneminde yüksek olan mikroplankton katkı oranlarının yaz mevsiminde yüzey tabakalarda azalarak yerini pikoplanktona bıraktığı tespit edilmiştir. Bölgede fitoplankton kompozisyonuna en fazla katkı yapan ikinci grup nanoplankton olurken özellikle klorofil maksimumun olduğu derinliklerde en yüksek katkı oranına ulaşmıştır. İstasyonlar açısından bir değerlendirme yapıldığında ise kıyı istasyonların fitoplankton katkı oranlarının genellikle daha yüksek olduğu tespit edilmiştir. Çalışma bölgesinde klorofil- $a$ baskın pigment olurken öne çıkan diğer pigmentler peridinin, fukoksantin ve 19'-heksanoloksifukoksantin olmuştur.

Anahtar Kelimeler: Fitoplankton boy grupları, HPLC, Karadeniz, Pigment

\section{Distribution of Pigment-Based Phytoplankton Size Classes in the South- Eastern Black Sea Coast}

\begin{abstract}
In the present study, the spatio-temporal pattern of marker pigment composition and phytoplankton size classes from December 2014 to August 2015 were investigated along the south-eastern coasts (Giresun-Artvin) of the Black Sea. Along the 12 stations, seasonal samplings were conducted from surface to $40 \mathrm{~m}$ depths with $10 \mathrm{~m}$ intervals. After the HPLC analyses, the contribution of phytoplankton size classes to total phytoplankton biomass varied between 1 and 71\%; 1 and 80\%; 8 and 93\% for picoplankton, nanoplankton and microplankton, respectively. In terms of seasonal evaluation, the contribution of microplankton was highest in winter and spring period and decreased throughout surface water in summer, which picoplankton were characterised with high contribution. The second important group in the area was nanoplankton. Its contribution increased highest values at the chlorophyll maxima. In terms of stations, the phytoplankton contribution rates of coastal stations were generally higher in the area. While chlorophyll- $a$ was the dominant pigment in the study area, other prominent pigments were peridinin, fucoxanthin and 19-hexanoloxyfucoxanthin.
\end{abstract}

Keywords: Phytoplankton size classes, HPLC, Black Sea, Pigment 


\section{Giriş}

Fitoplanktonik gruplar sahip oldukları fotosentetik kapasite ile yeryüzündeki birincil üretimin yaklaşık olarak \%50'sini (Falkowski vd., 2007; Boyce vd., 2010) ve neredeyse denizel üretimin de tamamın oluşturmaktadır (Mackas, 2011). Aynı zamanda, ekosistem içerisinde fotosentez ile toplam $\mathrm{CO}_{2}$ konsantrasyonunu etkilemekte ve pH dengesinin sağlanmasında da önemli bir role sahiptirler (Takahashi vd., 2002). Bu mekanizma ile antropojenik kaynaklı sera gazı emisyonunu $1 / 3$ oranında azaltmaktadırlar. Sahip oldukları bu önemli rollerinden dolayı, fitoplankton biyomasinın takibi ve tür kompozisyonunun tespiti pelajik ekosistemin dinamiklerinin ve yapısının anlaşılmasında oldukça önem arz etmektedir (Jeffrey ve Vesk, 1997; Ediger vd., 2006; Nair vd., 2008). Ayrica, fitoplanktonik gruplar bulundukları ortamın trofik seviyesi hakkında bilgi verirken (Barlow vd., 2004), gruplara özgü olan belirteç pigment oranları kullanılarak farklı biyo-coğrafik geçiş bölgelerinin ve su kütlelerinin yapısı da belirlenebilmektedir (Gibb vd., 2000).

Fitoplanktonik çalışmalar genellikle mikroskop kullanılarak yürütülmektedir. Klasik bir yöntem olan bu teknik türlerin taksonomik özelliklerinden faydalanılarak teşhis edilmesi sağlanmaktadır (Eker-Develi vd., 2008). Ancak, zaman alan (örnek hazırlanması, çöktürülmesi vb.) ve ciddi anlamda uzmanlık gerektiren bir teknik olması nedeniyle kısa zamanda fazla sayıda örnek çalışılmasına imkân vermemektedir. Diğer taraftan mikroskop çalışmalarının yetersiz kaldığ durumlarda, fitoplankton kompozisyonunun belirlenmesinde HPLC tekniği yaygın bir şekilde kullanılmaktadır (Mantoura ve Lleweellyn, 1983; Wright ve Shearer, 1984; Trees vd., 2000). Bu metodun temelinde farklı alg sınıflarının imza niteliğinde özel pigmentlere sahip olmaları yatmaktadır. $\mathrm{Bu}$ pigmentler belirteç pigment olarak isimlendirilirler.

Klorofil- $a$ fitoplankton biyomasinın belirlenmesinde uzun zamandır kullanılan temel fotosentetik pigmenttir (Boyce vd., 2010). Bu pigmentin yanı sira fitoplanktonik gruplara özgü belirteç pigmentler kullanılarak fitoplankton canlı kütlesi ve boy gruplarının katkısı da kolaylıkla ortaya konulabilmektedir (Uitz vd., 2006). Örneğin Bacillariophyta, Cyanophyta ve Chlorophyta için sirasıyla fukoksantin, zeaksantin ve klorofil- $b$ belirteç pigment olarak kullanılabilmektedir. Ayrıca bu pigmentlerin klorofil- $a$ pigmentine oranlar1 uygun faktörler ile kıyaslanarak deniz suyu örneğindeki fitoplankton boy gruplarının oransal dağılımı da belirlenebilmektedir (Gieskes ve Kraay, 1983; Wright vd., 1987; Wright vd., 1996; Obayashi vd., 2001; Ediger vd., 2006).

Klorofil- $a$ diğer pigmentlere göre çevresel değişimlere çabucak tepki verebildiğinden temel pigment olarak değerlendirilmektedir. $\mathrm{Bu}$ pigmentin yanı sira aksesuar pigment olarak bilinen ve alg gruplarının fizyolojik durumu ve taksonomik kompozisyonu hakkında bilgi veren pigmentler de bulunmaktadır. Aksesuar pigmentler 1şı̆ğın farklı dalga boylarındaki (400-700 nm) elektronları yakalar ve fotosisteme aktararak fotosenteze katk1 yaparlar. Her alg sınıfı farklı dalga boyundaki 1şı̆̆ kullanma yeteneğine sahip olduğunda derinliğe bağlı olarak alg gruplarının etkinliği de değişiklik gösterir. Pigmentlerin bu özelliklerden yola çıkılarak fitoplanktonik grupları taksonomik olarak tanımlamada çeşitli "pigment indeksleri" kullanılmaktadır (Vidussi vd., 2001). Bu amaçla fitoplanktonik grupları temsilen yedi ana pigment (Fukoksantin, Peridinin, 19Heksanoloksifukoksantin, 19Heksanoloksifukoksantin, Alloksantin, Klorofil- $b$ ve Zeaksantin) kullanılır. Bütün bunların toplamı "diyagnostik pigment" olarak tanımlanır (Uitz vd., 2006);

Dünyanın en büyük anoksik havzalarından biri olan Karadeniz'de fitoplanktonun yapısal ve 
fonksiyonel karakteristikleri ekosistem ile yakından ilgilidir. $\mathrm{Bu}$ nedenle planktonik organizmalar ekosistemin durumunu tanımlamak için indikatör olarak kullanilabilmektedir (Yunev vd., 2002). Karadeniz'in öfotik bölgesi pigment karakterizasyon çalışmaları için ideal bir çevre sağlamaktadır. Karadeniz'de fitoplankton biyokütlesi ve pigment içeriklerinin belirlenmesine yönelik çalışmalar son 20 yıl içerisinde hız kazanmıştır. Ancak, Karadeniz'in Anadolu sahillerinde fitoplankton biyomasının zamana bağlı değişimi konusunda yürütülen çalışmalar çoğunluktayken özellikle pigment kompozisyonu ve pigmente dayalı fitoplankton boy gruplarının belirlenmesine yönelik çalışmalar oldukça sınırlıdır (Ediger vd., 2006; Ağırbaş, 2010; Eker-Develi vd., 2012; Koca, 2014). Bu çalışma ile Güneydoğu Karadeniz kıyılarında (Artvin-Giresun) belirteç pigment konsantrasyonları ve pigmente dayalı fitoplankton boy gruplarının zamansal ve alansal değişimi ortaya konulmaya çalışılmıştır.

\section{Materyal ve Metot}

\subsection{Saha Çalışmaları}

Deniz çalışmaları, Güney Doğu Karadeniz (Artvin-Giresun)'de belirlenen farklı karakterlerdeki $(2,8$ ve 15 deniz mili) istasyonlarda Kasım 2014-Ağustos 2015 tarihleri arasinda mevsimsel olarak yürütülmüştür (Şekil 1).

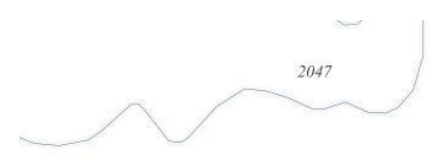

\section{KARADENIZ}

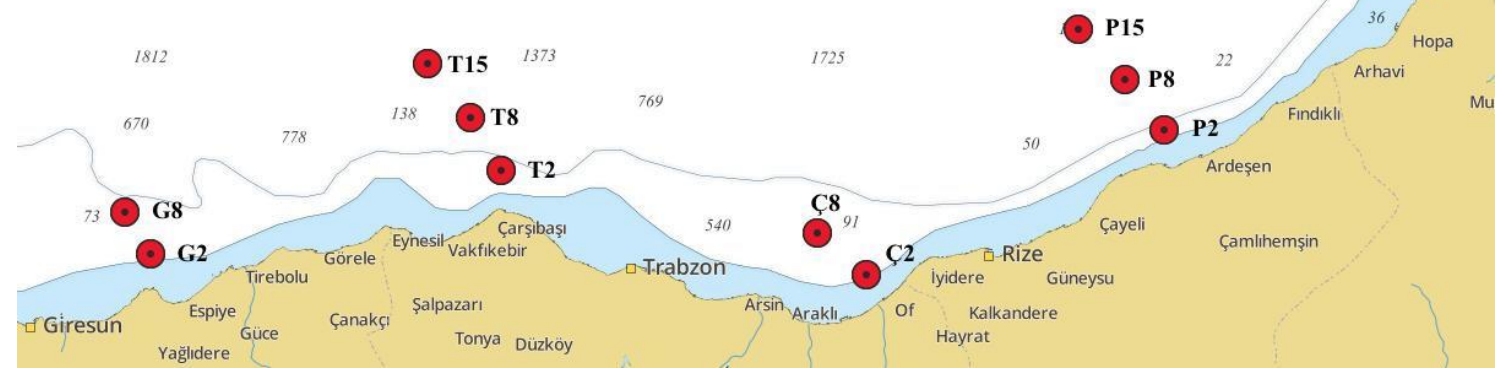

Şekil 1. Çalışma bölgesi ve örnekleme istasyonları (G2: Giresun 2 mil; G8: Giresun 8 mil; T2: Trabzon 2 mil; T8: Trabzon 8 mil; T15: Trabzon 15 mil; Ç2: Çamburnu 2 mil; Ç8: Çamburnu 8 mil; P2: Pazar 2 mil; P8: Pazar 8 mil; P15: Pazar 15 mil; K2: Kemalpaşa 2 mil; K8: Kemalpaşa 8 mil)

Figure 1. Study area and sampling points (G2: Giresun 2 miles; G8: Giresun 8 miles; T2: Trabzon 2 miles; T8: Trabzon 8 miles; T15: Trabzon 15 miles; C2: Camburnu 2 miles; C8: Camburnu 8 miles; P2: Pazar 2 miles; P8: Pazar 8 miles; P15: Pazar 15 miles; K2: Kemalpasa 2 mileses; K8: Kemalpasa 8 miles)

Deniz suyu örnekleri öfotik bölge içerisinde yüzeyden itibaren 10 metre aralıklar ile $40 \mathrm{~m}$ derinliğe kadar örneklenmiştir. Pigment analizleri için gerekli olan deniz suyu örnekleri SBE 32 Carousel 12 şişeli su örnekleme cihazı ile toplanmıştır. Deniz suyuna ait hidrografik ölçümler SBE 25 CTD prob kullanılarak gerçekleştirilmiştir. Saha çalışmaları Trabzon Su Ürünleri Merkez Araştırma Enstitüsü bünyesinde bulunan R/V SÜRAT ARAŞTIRMA I gemisi ile yürütülmüştür.

\subsection{HPLC Analizleri}

HPLC ile pigment analizi Mantoura ve Llewelyn (1983)'e göre yapılmıştır. Yöntemde; koyu renkli polietilen şişelerle istenilen derinlikten alınan 1 lt deniz suyu örneği düşük vakum basıncı altında $(0,5 \mathrm{~atm}$ den daha az) $47 \mathrm{~mm}$ çaplı GF/F filtrelerden süzülmüştür. Daha sonra filtreler analiz edilene kadar sıv1 azot içerisinde $\left(-196^{\circ} \mathrm{C}\right)$ muhafaza edilmiştir. Ekstraksiyon işlemini hızlandırmak için \%90'lık HPLC cinsi aseton $(5 \mathrm{ml})$ içerisine konulan filtreler analiz 
öncesinde sonikatör (1 dakika için $60 \mathrm{~Hz}$, SonicPlus) yardımıyla parçalanmıştır. Daha sonra örnekler bir gece karanlık ortamda +4 ${ }^{\circ} \mathrm{C}$ 'de buzdolabında bekletilerek ekstraksiyonun tamamlanması sağlanmıştır. Analiz öncesinde örnekler 3500 rpm devirde 10 dakika süreyle hücresel parçaları ortadan kaldırmak amacıyla santrifüj edilmiştir. Analizler C8 kolon ve DAD dedektör kullanılarak SHIMADZU marka HPLC cihazı ile gerçekleştirilmiştir. Ölçüm için, ekstrakt içerisinden $500 \mu$ l örnek alınarak $0,2 \mu \mathrm{m}$ lik millipore filtrelerden süzülüp ve $500 \mu 1$ 1M Amonyum Asetat İyon çözeltisiyle karıştırılmıştır. Tamponlu ekstraktan $100 \mu 1$ alınarak Thermo Hypersil MOS-2 C8 kolonuna $(150 \times$ x $4,6 \mathrm{~mm}, 3 \mu \mathrm{m}$ particle size, $120 \AA$ pore size ve $\% 6,5$ carbon loading) ve $50 \quad \mu 1$ loop'a sahip HPLC sistemine enjekte edilmiştir. Pigmentlerin linear eğimli çift mobil faz sistem kullanılarak ayrılması sağlanmıştır. Mobil fazlar metanol ve $1 \mathrm{M}$ amonyum asetattan $(80: 30 \mathrm{v} / \mathrm{v})$ oluşan mobil faz A ve $\% 100$ metanol'den oluşan mobil faz B'den oluşmaktadır. Pigmentlerin pik alanları 1 $\mathrm{ml} / \mathrm{dk}$ 'lık düşük akım altında linear eğimle belirlenmiştir (dakika, \% mobil faz A, \% B mobil faz): (0;75; 25), (1; 50; 50), (20; 30; 70), (25; $0 ; 100), \quad 32 ; 0 ; 100)$. Analiz sonras1 veri toplanmas1 ve entegrasyonu LC solution yazılımı kullanılarak yapılmıştır.

HPLC sistemi her pigment için ticari standartlar (klorofil a, b: Sigma Kolonu; klorofil c2, klorofil c3, perid, 19-but, fuco, 19 hex, diadinoxanthin, allo, lutein, zea, divinil klorofil-a ve $\beta$ karoten: VKI, Danimarka) kullanılarak kalibre edilmiştir. Klorofil- $a$ ve marker pigmentler için belirleme sinırı 0,005-0,007 $\mu \mathrm{g} / \mathrm{l}$ dir.

Pigment konsantrasyonları aşağıdaki denkleme göre hesaplanmıştır,

$\mathrm{Cp}=\frac{\mathrm{Ap} \times \text { Vext } \times 10}{\mathrm{~B} \times \text { Vfilt } \times \text { Vinj } \times 1000 \times \mathrm{Rf}}$

$\mathrm{Cp}\left(\mu \mathrm{gL}^{-1}\right)=$ Pigment konsantrasyonu
Ap $\left(m A U^{*} s\right)=$ Pik alanı

Rf $\left(\right.$ ngmAU $\left.{ }^{-1}\right)=$ Kalibrasyon eğrisinin eğimi (ng kolon ${ }^{-1}$ )

$V_{\text {filt }}(1)=$ Süzülen su hacmi

$\mathrm{V}_{\text {ext }}(\mathrm{ml})=$ Ekstraksiyon için kullanılan çözücü hacmi

$\mathrm{V}_{\text {inj }}(\mu \mathrm{l})=$ Kromotagrafi sistemine enjekte edilen örnek hacmi

$\mathrm{B}=$ Tampon seyreltme faktörü

\subsection{Farklı Boy Sınıfındaki Fitoplanktonik Grupların Belirlenmesi}

Fitoplanktonik gruplar ve bunların toplam fitoplankton biyokütlesine yaptığ1 katk1 oranlar1 (\%) Vidussi vd. (2001)'e göre belirlenmiştir:

$\Sigma \mathrm{DP}_{\mathrm{W}}=1,41 *[$ Fuco $]+1,41 *[$ Perid $]+1,27 *[\mathrm{Hex}-$ fuco $+0,35 *$ [But-fuco $]+0,60 *$ [Allo]

$+1,01 *[\mathrm{TChlb}]+0,86 *[\mathrm{Zea}]$

$\mathrm{f}_{\text {mikro }}:(1,41 *[$ Fuco $]+1,41 *[$ Perid $]) / \Sigma D P_{W}$

$\mathrm{f}_{\text {nano }}:(1,27 *[$ Hex-fuco $]+0,35 *[$ But-

fuco $]+0,60 *[$ Allo $]) / \Sigma \mathrm{DP}_{\mathrm{W}}$

$\mathrm{f}_{\text {piko }}:(1,01 *[\mathrm{TChlb}]+0,86 *[\mathrm{Zea}]) / \Sigma \mathrm{DP} \mathrm{W}_{\mathrm{W}}$

$\mathrm{f}_{\text {mikro }}$ : mikroplankton fraksiyonu ( $\left.\geq 20 \mu \mathrm{m}\right)$

$\mathrm{f}_{\text {nano }}:$ nanoplankton fraksiyonu $(2-20 \mu \mathrm{m})$

$\mathrm{f}_{\text {piko }}$ : pikoplankton fraksiyonu $(\leq 0,2-2 \mu \mathrm{m})$

\section{Bulgular}

\subsection{Sıcaklık ve Tuzluluk Değișimi}

Çalışma bölgesinde deniz suyu yüzey sıcaklığı $8^{\circ} \mathrm{C}$ (Şubat 2015) - $28^{\circ} \mathrm{C}$ (Ağustos 2015) arasında değişim göstermiştir. Şubat 2015 döneminde dikey karışımlarla birlikte mevsimsel termoklin tamamen ortadan kalkmıştır. Mayıs 2015 dönemine gelindiğine ise mevsimsel termoklin tabakasının yeniden 
şekillenmeye başladığı tespit edilmiştir. Ağustos 2015 döneminde ise deniz suyu yüzey sıcaklığı en yüksek seviyeye ulaşırken bu dönemde mevsimsel termoklin tabakası (20-30 m) daha da belirgin bir hal almıştır.

Tuzluluk profilleri ise Karadeniz'in genel karakteristiğine uygun (\%o 17-18) bir yap1 sergilerken derinlikle beraber \%o 20 seviyelerine ulaşmıştır. Özellikle nehir girdisine yakın olan istasyonlarda (Kemalpaşa, Pazar ve Çamburnu) ve yağışların etkili olduğu Şubat ve Mayıs dönemlerinde yüzey suyu tuzluluk değerleri \%o 16'ya kadar düşmüştür.

\subsection{Pigment Kompozisyonu}

Çalışmanın süresince pigment konsantrasyonları alansal ve zamansal olarak önemli değişimler göstermiştir. Fitoplankton biyomasının bir göstergesi olan ve temel fotosentetik pigment olarak kabul edilen klorofil-a kıyısal sularda genellikle yüksek konsantrasyonlarda olup açığa gidildikçe düşüş göstermiş̧ir. Sonbahar ve kış mevsiminde yüzey ve yüzey altı derinliklerde $(20-30 \mathrm{~m})$ yüksek konsantrasyonlarda olan klorofil- $a$, ilkbahar ve yaz mevsiminde ise daha alt derinliklerde (30-40 m) yüksek konsantrasyonlara ulaşmışıı (Şekil 2). Aksesuar pigmentlerden olan peridinin sonbahar mevsiminde yüzey tabakalarda belirgin bir şekilde yüksek konsantrasyonlara ulaşırken kış ve ilkbahar mevsimlerinde ise su kolonu içerisinde daha homojen bir yap1 sergilemiştir. Yaz mevsiminde ise alt derinliklerde (20-40 m) yüksek konsantrasyonlara ulaşmıştır (Şekil 3). Fukoksantin pigmenti sonbahar mevsiminde öne çıkarken kış mevsiminde yüzey altı derinliklerde $(10-20 \mathrm{~m})$ ve yaz mevsiminde ise daha derinlerde (30-40 m) yüksek konsantrasyonlara ulaşmıştır (Şekil 4). Bölgede öne çıkan diğer aksesuar pigment 19Heksanoloksifukoksantin olmuştur. Bu pigment ağırlıklı olarak sonbahar ve kış mevsiminde yüksek konsantrasyonlara ulaşmıştır (Şekil 5). Karadeniz'in bir dinamiği olarak mevsimsel termoklin tabakasının çok belirgin olduğu yaz döneminde yüzey tabakalar pigment konsantrasyonu açısından daha fakir bir yap1 göstermiş ve derinlikle beraber $(30-40 \mathrm{~m})$ yüksek konsantrasyonlara ulaşmıştır.

Kasım 2014 döneminde öne çıkan pigmentler başta klorofil- $a$ olmak üzere peridinin, fukoksantin ve 19-Heksanoloksifukoksantin pigmentleri olmuştur. Temel fotosentetik pigment olan klorofil- $a$ konsantrasyonu bu dönemde 0,129-5,230 $\mu \mathrm{g} / 1$ arasında değişim göstermiştir (Şekil 2A). Peridinin, dinoflagellatlar için belirteç nitelikte olan bir pigment olup konsantrasyonu 0,135-3,485 $\mu \mathrm{g} / 1$ aralığında değişmiştir (Şekil 3A). Fukoksantin diatomlar için belirteç olan bir pigmenttir. $\mathrm{Bu}$ dönemde konsantrasyonları 0,079-2,517 $\quad \mu \mathrm{g} / 1 \quad$ aralığında değişim göstermiştir (Şekil 4A). 19'Heksanoloksifukoksantin kokolitoforlar için belirleyici özellik taşımakta olup konsantrasyonları 0,060-0,991 $\mu \mathrm{g} / 1$ aralığında değişim göstermiştir (Şekil 5A).

Şubat 2015 döneminde öne çıkan pigmentler klorofil- $a$, peridinin, fukoksantin, 19'Hekanoloksifukoksantin ve klorofil- $b$ olmuştur. $\mathrm{Bu}$ dönemde klorofil- $a$ konsantrasyonu $\quad 0,156-5,945 \mu \mathrm{g} / 1$ aralığında değişim göstermiştir (Şekil 2B). Peridinin konsantrasyonu $0,168-1,349 \mu \mathrm{g} / 1$ aralığında değişim göstermiştir (Şekil 3B). Fukoksantin konsantrasyonları 0,334-1,785 $\mu \mathrm{g} / 1$ aralığında değişim göstermiştir (Şekil 4B). Mavi-yeşil algler ve yeşil algler için belirteç pigment niteliğinde olan klorofil- $b$ konsantrasyonları bu dönem içinde 0,057-0,724 $\mu \mathrm{g} / 1$ arasında değişim göstermiştir. Öne çıkan diğer bir pigment olan 19'-Heksanoloksifukoksantin konsantrasyonları $0,061-2,562 \mu \mathrm{g} / 1$ arasinda değişim göstermiştir (Şekil 5B).

May1s 2015 döneminde klorofil- $a$ konsantrasyonu $\quad 0,157-3,748 \mu \mathrm{g} / 1$ aralığında değişim gösterirken (Şekil 2C), peridinin, fukoksantin, klorofil- $b$ ve 19'Hekanoloksifukoksantin konsantrasyonları sirasiyla 0,143-0,922 $\mu \mathrm{g} / 1,0,024-0,896 \mu \mathrm{g} / \mathrm{l}$, $0,040-0,803 \quad \mu \mathrm{g} / 1 \quad$ ve $\quad 0,044-0,754 \quad \mu \mathrm{g} / 1$ 
aralığında değişim göstermiştir (Şekil 3-5C).

Ağustos 2015 döneminde klorofil- $a$ konsantrasyonu $\quad 0,179-4,987 \mu \mathrm{g} / 1$ aralığında değişim göstermiştir (Şekil 2D). Peridinin konsantrasyonu $\quad 0,145-3,296 \mu \mathrm{g} / 1$ aralı̆̆ında değişim göstermiştir (Şekil 3D). Fukoksantin; bu dönem içerisinde 0,076-1,681 $\mu \mathrm{g} / \mathrm{l}$ aralığında değişim göstermiştir (Şekil 4D). Klorofil- $b$ konsantrasyonları 0,074-0,432 $\mu \mathrm{g} / 1$ aralığında değişim göstermiştir. 19'Hekanoloksifukoksantin konsantrasyonları 0,031-0,624 $\mu \mathrm{g} / 1 \quad$ aralığında değişim göstermiştir (Şekil 5D). Klorofil- $b$ pigmentinin yanı sıra zeaksantin pigmenti de mavi-yeşil algler ve yeşil algler için belirleyici pigment özelliği taşımaktadır. Bu dönemde zeaksantin konsantrasyonu $0,054-0,998 \mu \mathrm{g} / 1$ aralığında değişim göstermiştir.
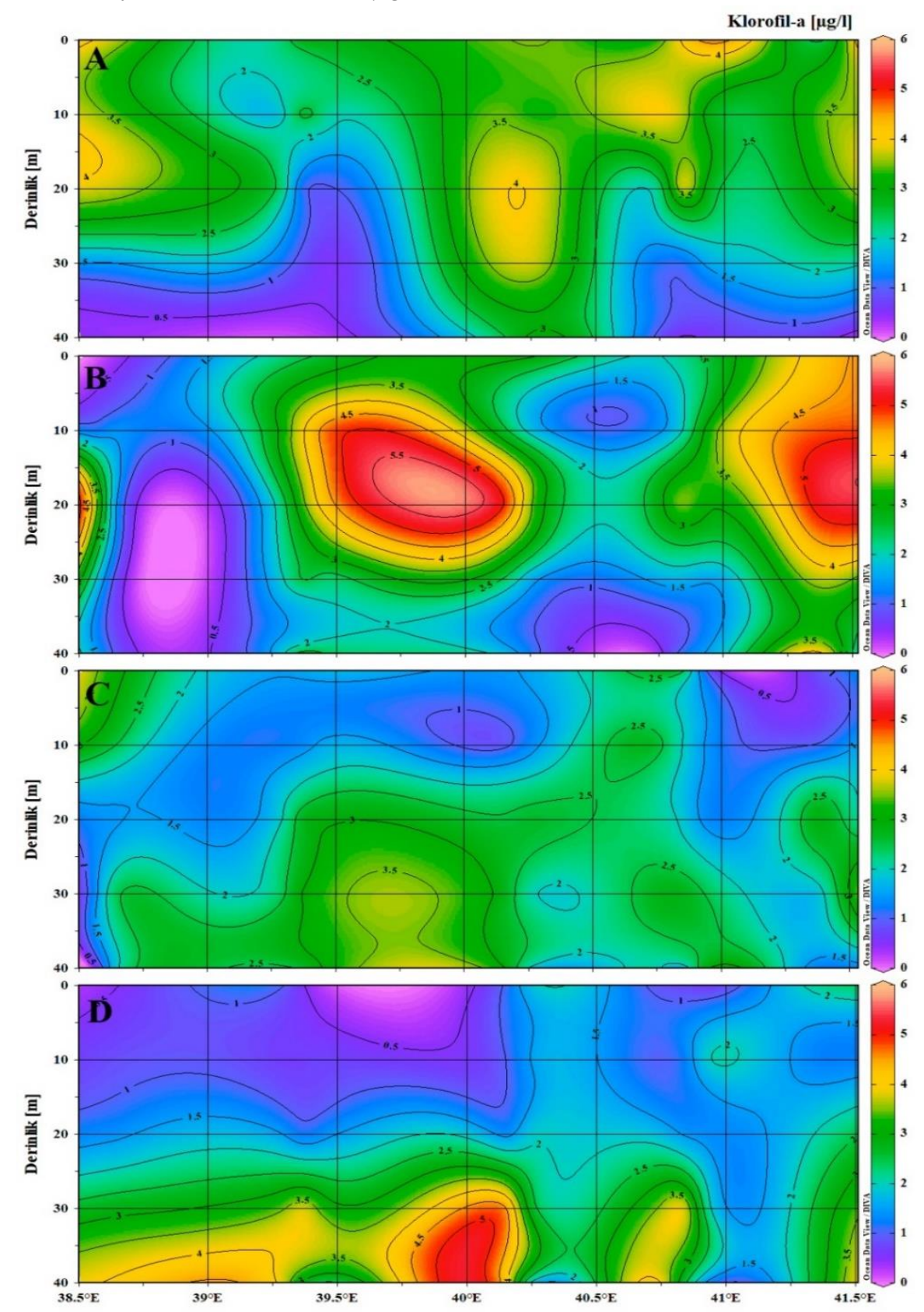

Boylam

Şekil 2. Çalışma bölgesinde klorofil- $a$ konsantrasyonun su kolonundaki değişimi (A: Kasım 2014, B: Şubat 2015, C: Mayıs 2015, D: Ağustos 2015).

Figure 2. Chlorophyll-a variation in water column along the study area (A: November 2014, B: February 2015, C: May 2015, D: August 2015). 

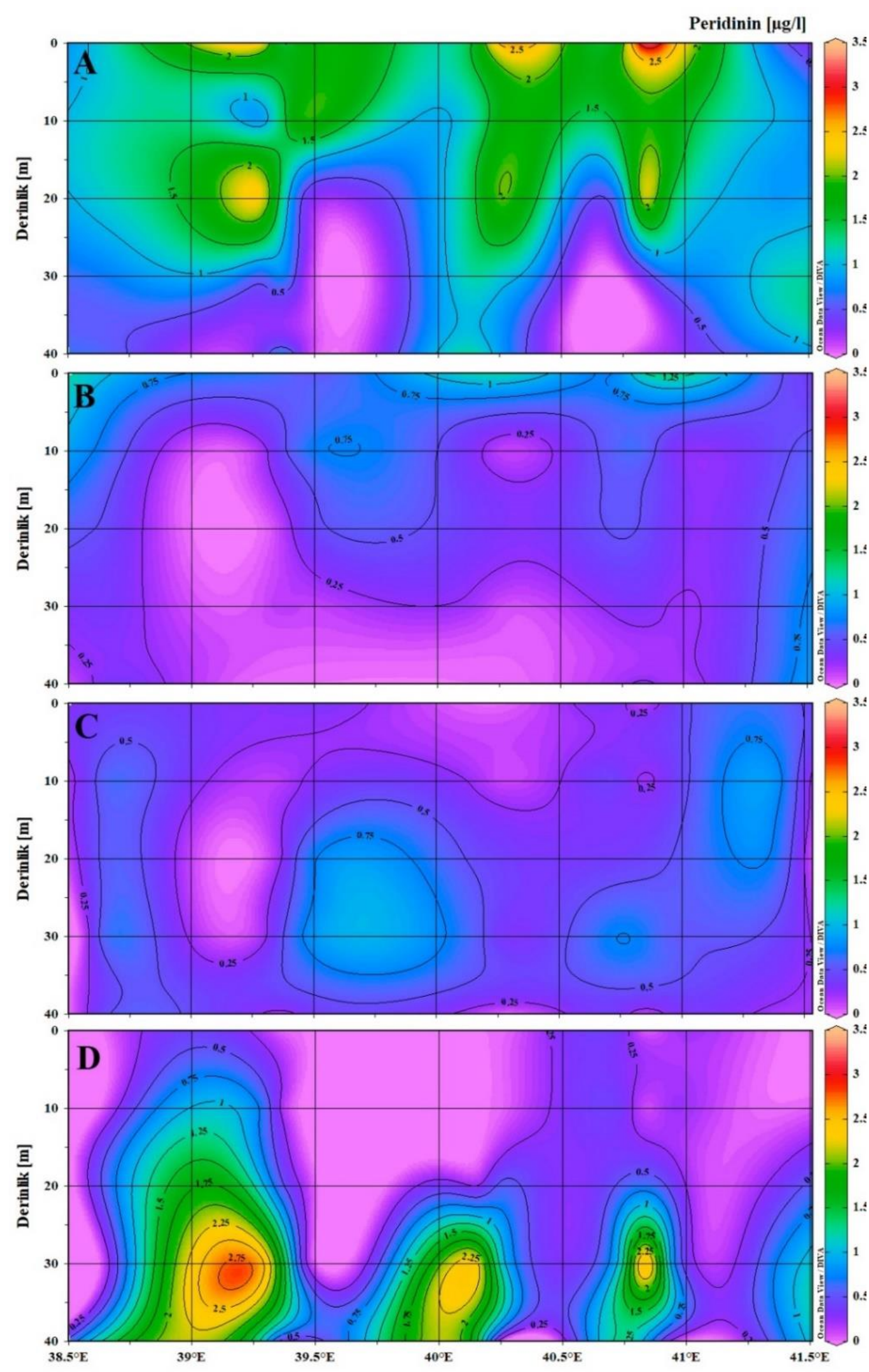

Boylam

Şekil 3. Çalışma bölgesinde peridinin konsantrasyonun su kolonundaki değişimi (A: Kasım 2014, B: Şubat 2015, C: Mayıs 2015, D: Ağustos 2015).

Figure 3. Peridinin variation in water column along the study area (A: November 2014, B: February 2015, C: May 2015, D: August 2015). 

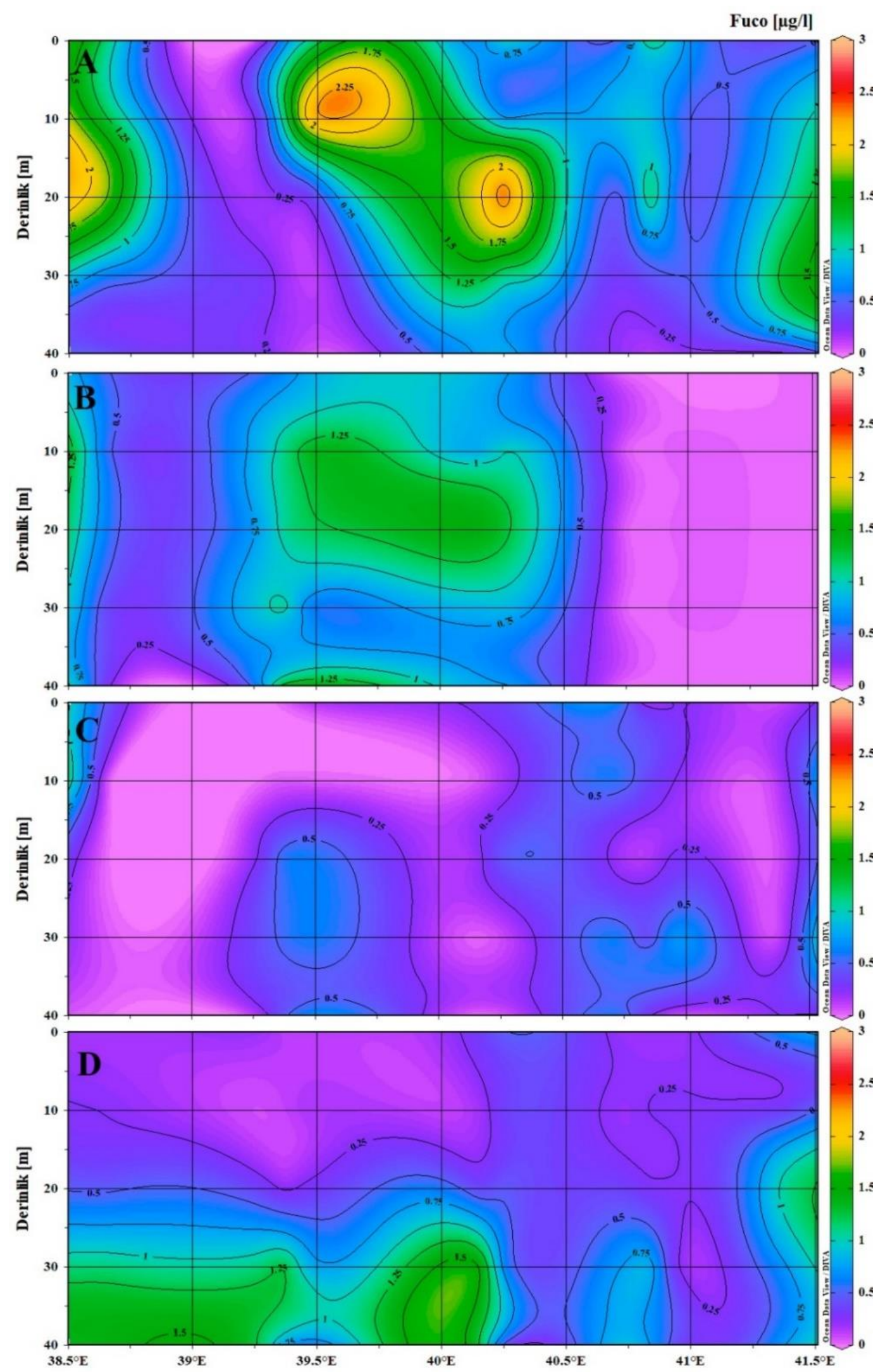

\section{Boylam}

Şekil 4. Çalışma bölgesinde fukoksantin konsantrasyonun su kolonundaki değişimi (A: Kasım 2014, B: Şubat 2015, C: Mayis 2015, D: Ağustos 2015).

Figure 4. Fucoxanthin variation in water column along the study area (A: November 2014, B: February 2015, C: May 2015, D: August 2015). 

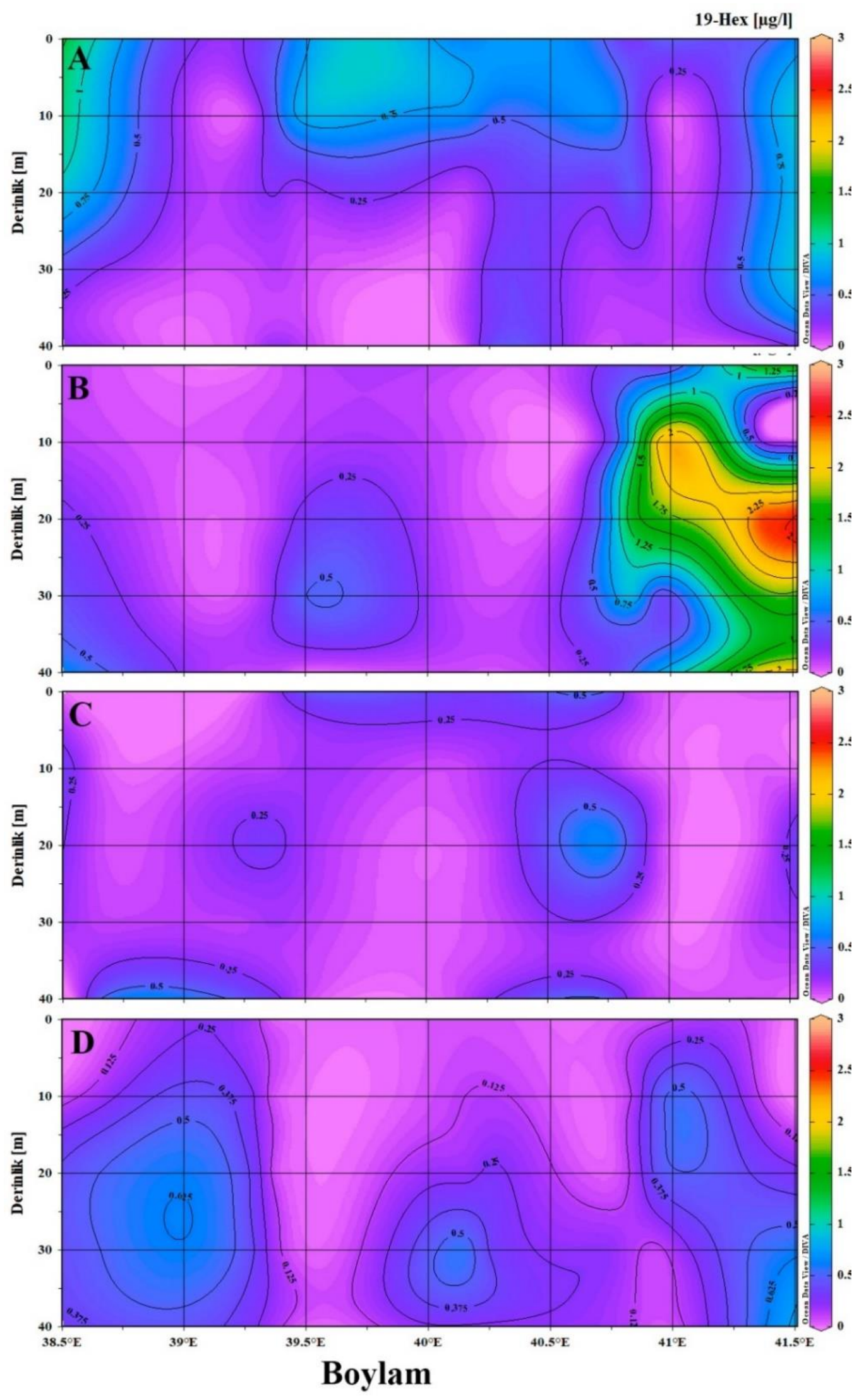

Şekil 5. Çalışma bölgesinde 19-Heksanoloksifukoksantin konsantrasyonun su kolonundaki değişimi (A: Kasım 2014, B: Şubat 2015, C: Mayıs 2015, D: Ağustos 2015).

Figure 5. 19-Hexanoyloxifucoxanthin variation in water column along the study area (A: November 2014, B: February 2015, C: May 2015, D: August 2015) 


\subsection{Pigmente Dayalı Fitoplankton Boy Grupları}

Pigment konsantrasyonları ile uygun eşitlikler kullanilarak hesaplanan fitoplankton boy gruplarının fitoplankton kompozisyonuna yaptığı katkı gerek grup bazında gerekse istasyonlar bazında şekil 6-8'de sunulmuştur.
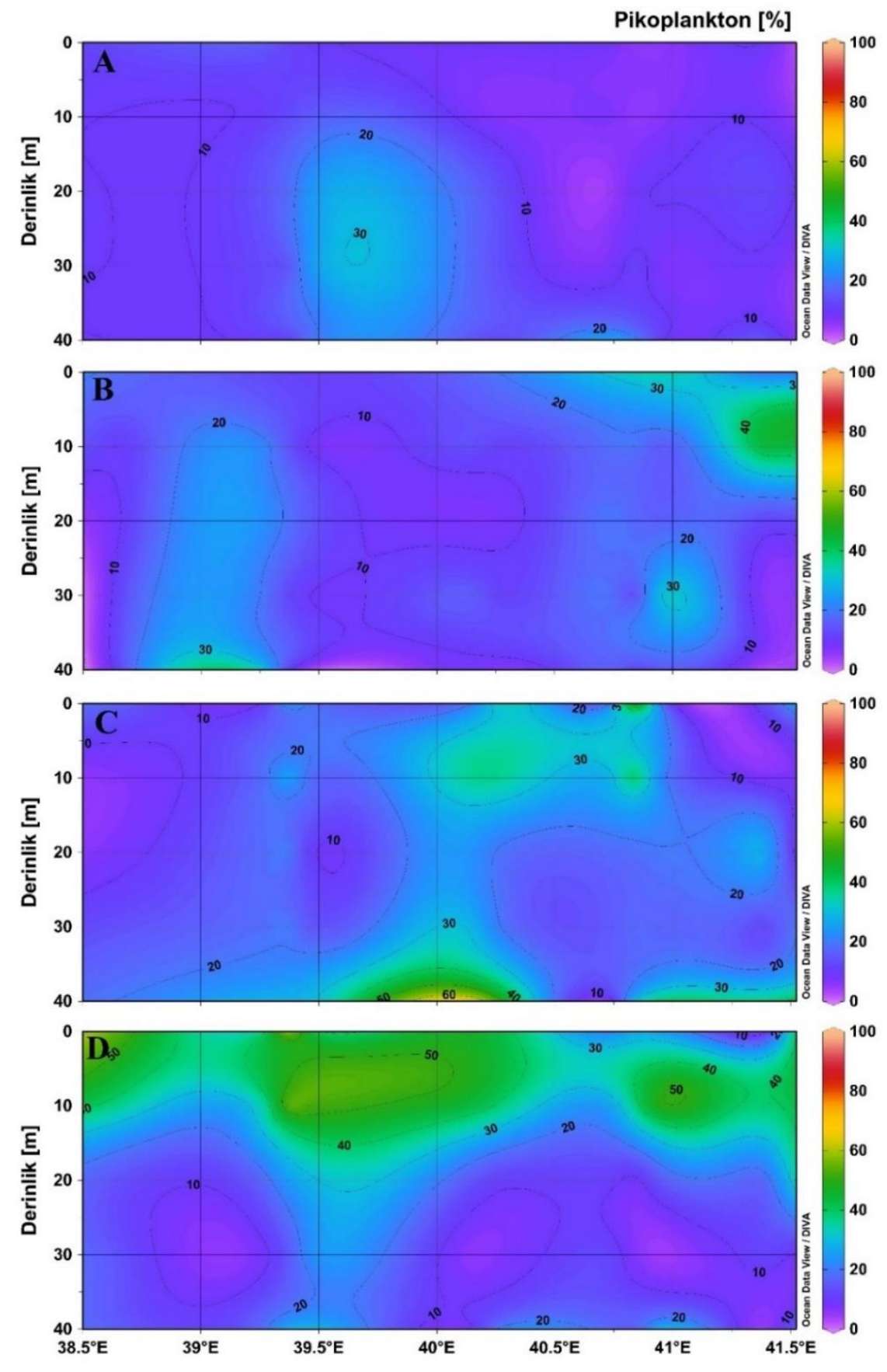

Boylam
Genel olarak mikroplankton hariç diğer grupların katkısı sonbahar döneminde düşük olup ilkbahar mevsimine doğru artı̧ göstererek en yüksek seviyelere ulaşmıştır. Çalışma bölgesinde mikroplankton en fazla katkı yapan grup olurken bunu nanoplankton ve pikoplankton takip etmiştir. 

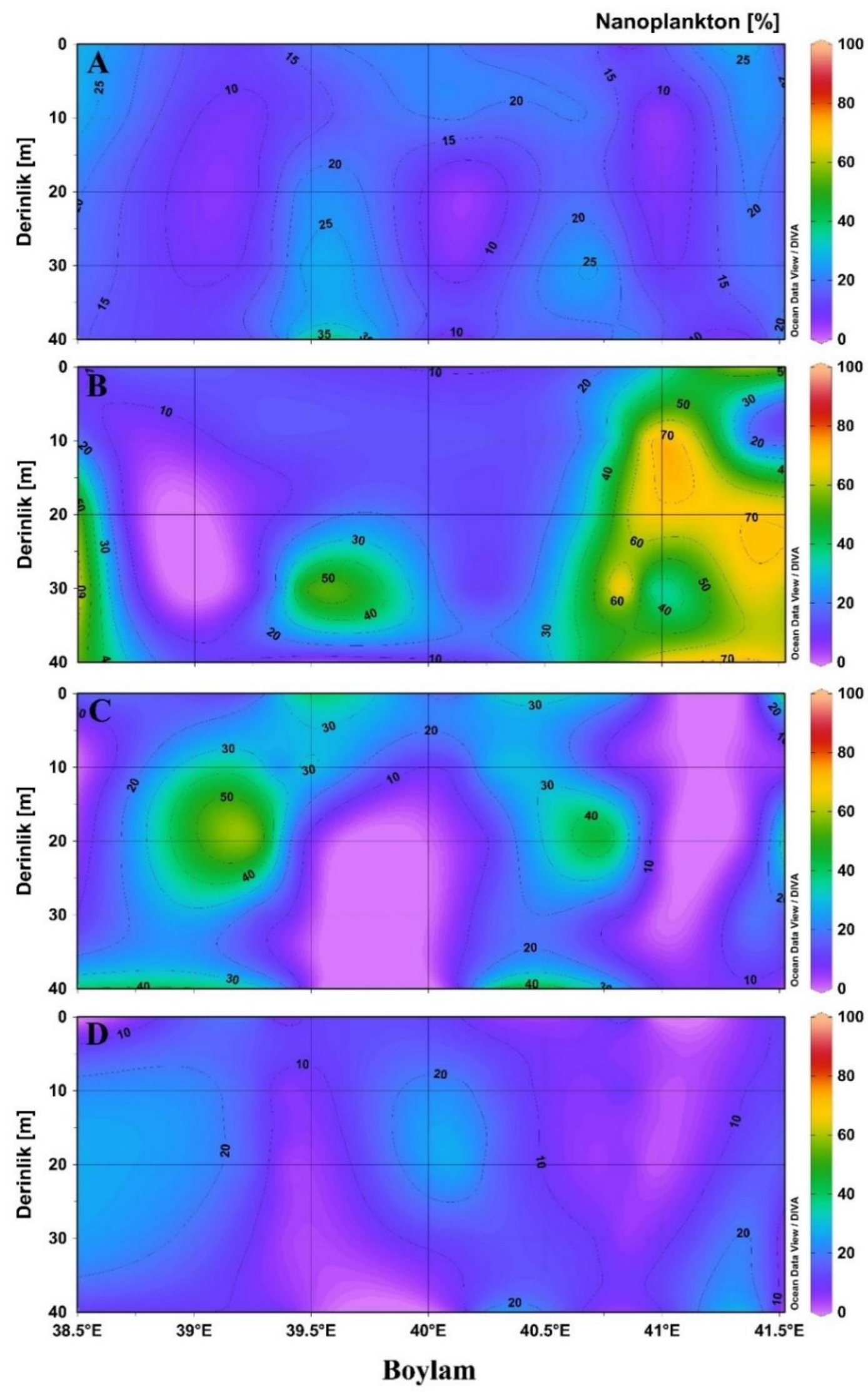

Şekil 7. Çalışma bölgesindeki nanoplanktonun su kolonunda toplam fitoplankton kompozisyonuna yaptığ katk1 (A: Kasım 2014, B: Şubat 2015, C: Mayıs 2015, D: Ağustos 2015).

Figure 7. Contribution of nanoplankton to total phytoplankton composition in water column along the study area (A: November 2014, B: February 2015, C: May 2015, D: August 2015). 

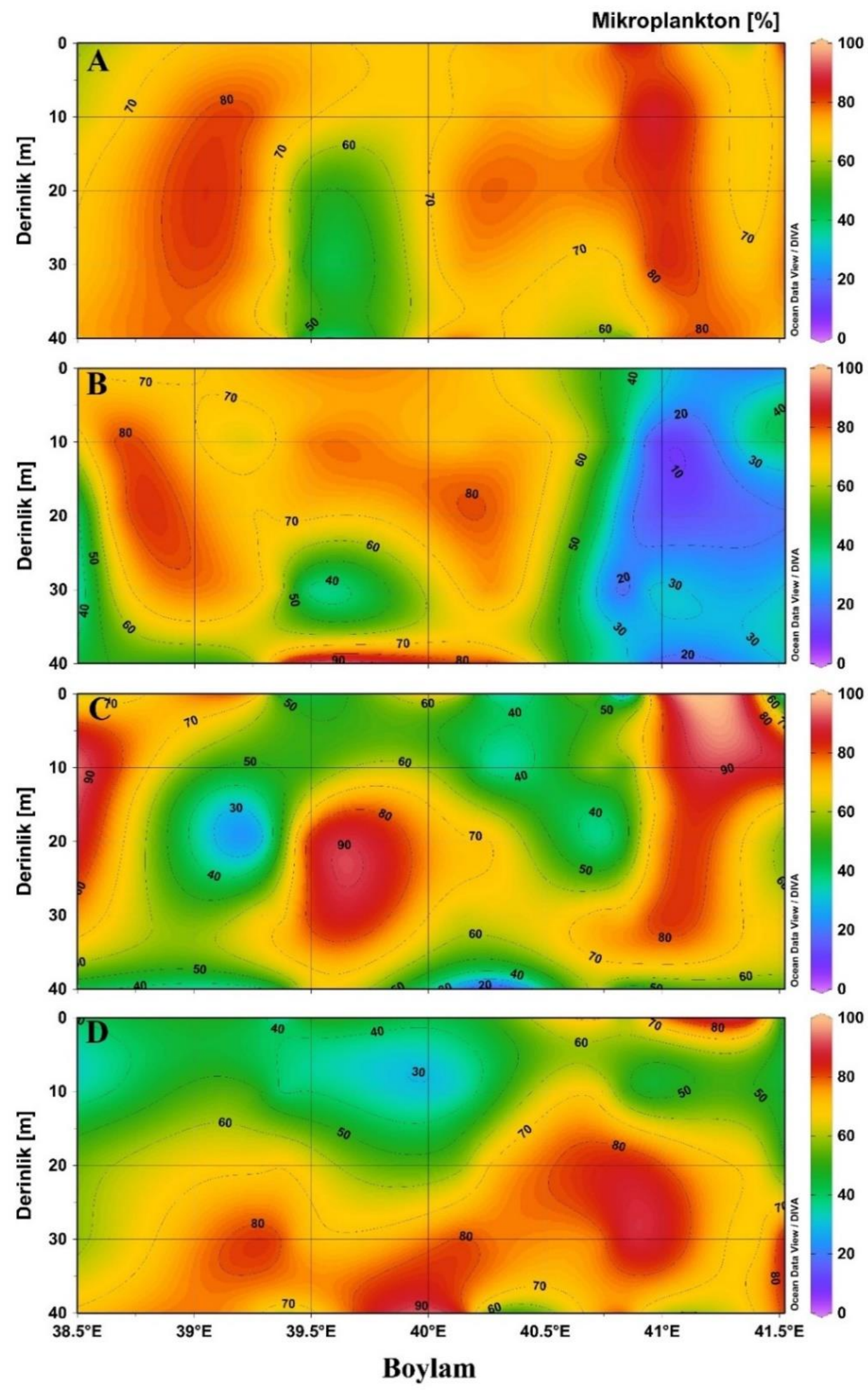

Şekil 8. Çalı̧̧ma bölgesindeki mikroplanktonun su kolonunda toplam fitoplankton kompozisyonuna yaptığı katkı (A: Kasım 2014, B: Şubat 2015, C: Mayıs 2015, D: A ğustos 2015).

Figure 8. Contribution of microplankton to total phytoplankton composition in water column along the study area (A: November 2014, B: February 2015, C: May 2015, D: August 2015). 
Kasım 2014 (sonbahar) döneminde mikroplankton en fazla katk1 (\%41-89) yapan grup olurken, katk1 oranları \%40 seviyesinin altına hiç inmemiştir. Bu grubu nanoplankton takip ederken bu dönemde en az katkısı olan grup pikoplankton olmuştur. Nanoplanktonun katkısı \%4-40 arasında değişirken pikoplanktonun katkıs1 genellikle \%30 seviyesinin altında kalmıştır. Bu iki grup derinliğe göre (20 m'den sonra) nispeten artış gösterse de bu artış nanoplankton için \%40 ve pikoplankton için $\% 25$ seviyelerini geçmemiştir (Şekil 6-8).

Karışımların olduğu ve termoklin tabakasının kaybolduğu Şubat 2015 (kış) döneminde grupların katkı oranlarında önemli değişimler gözlenmiştir. Genel olarak bu dönemde de mikroplankton baskınlığı dikkat çekmektedir ancak oranları \%80'in altında kalmıştır. Bu dönemde nanoplankton gruplarının katkısı önemli ölçüde artış göstermiş zaman zaman \%80 seviyelerine ulaşmıştır. Pikoplankton katkısı en az olan $(<\% 40)$ grup olurken önceki döneme göre yüzey tabaklarda (10-15 m) artış göstermiştir (Şekil 6-8).

Yeni besin tuzu girdisinin olduğu Mayıs 2015 (ilkbahar) döneminde mikroplankton en fazla katk1 yapan grup olurken, katk1 oranlar1 \%90 seviyelerine kadar ulaşmıştır. Bir önceki döneme göre nanoplanktonun katkısı azalırken pikoplanktonun katkısı artmış ve zaman zaman yüzey sularında \%60'ın üzerine çıkmıştır. Derinliğe bağlı bir değerlendirme yapıldığında mikroplankton 10 m'de en yüksek katk1 oranına ulaşırken nanoplankton en fazla katkıyı $20 \quad \mathrm{~m}$ derinlikte yapmıştır. Pikoplankton ise daha derinlerde $(40 \mathrm{~m})$ en yüksek katkı oranına ulaşmıştır. Bölgesel dağılımları incelendiğinde coğrafi olarak birbirine yakın olan istasyonların (Trabzon ve Çamburnu) özellikle mikro- ve nanoplankton için benzer değişimler gösterdiği görülmektedir (Şekil 6-8).

Mevsimsel termoklin tabakasının şekillendiği Ağustos 2015 (yaz) döneminde yüzey sularında pikoplanktonun katkısı önemli oranda artış göstererek 10 m'den sonra önemli ölçüde azalmıştır. $\mathrm{Bu}$ dönemde nanoplanktonun katkısı çok düşük değerlerde $(<\% 20)$ tespit edilmiştir. Yüzey sularında \%4080 arasında olan mikroplanktonun katkıs1 termoklin tabakasının başladığı derinliğe kadar $(20 \mathrm{~m})$ azalmış ve termoklin tabakasından sonra tekrar artış göstermiştir (Şekil 6-8).

\section{Tartışma ve Sonuçlar}

Sucul ekosistemlerin ve özellikle denizlerin yapısının ve işleyişinin anlaşılmasında fitoplankton kompozisyonunun sürekli takip edilmesi büyük önem taşımaktadır. Bu amaçla geleneksel bir yöntem olan mikroskobik hücre sayım tekniği uzun yıllardır kullanılmaktadır. Mikroskopla tanımlama tekniğinin yanı sıra fitoplankton boy grupları için belirleyici nitelikte olan belirteç pigmentler ve oranları kullanılarak fitoplankton topluluklarının kompozisyonu HPLC tekniği ile daha hızlı bir şekilde ortaya konulabilmektedir.

HPLC tekniği birçok araştırma gurubu tarafindan (Wright ve Jeffrey, 1987; Gieskes, 1991; Millie vd., 1993; Jeffrey ve Vesk, 1997, Gibb vd., 2000, 2001; Barlow vd., 2002, 2004; Aiken vd., 2009; Ağırbaş vd., 2015; Yücel, 2017; Yücel ve Uysal, 2017; Yücel vd., 2017) uzun zamandan beri yaygın bir şekilde kullanılmaktadır. Karadeniz'de ise bu tekniğe dayalı çalışmalar oldukça sınırlıdır (Ediger vd., 2006; Eker-Develi vd., 2012; Ağırbaş, 2010; Koca, 2014). Karadeniz'de yürütülen çalışmaların ağırlıklı olarak daha çok yüzey suyu klorofil- $a$ konsantrasyonlarının belirlenmesine yönelik çalışmalar olduğu görülmektedir. Yerinde ölçüm tekniği ile gerçekleştirilen çalışmalar incelendiğinde ise Güney Karadeniz kiyılarında 1995-1996 dönemi için klorofil-a değerleri $0,1-1,5 \mu \mathrm{g} / 1$ arasında değişim göstermiştir (Yılmaz vd., 1998). Türkiye kıyılarını kapsayacak şekilde 1996-1998 dönemleri arasında yüzey klorofil- $a$ değerleri sirasıyla $0,34-0,42 \mu \mathrm{g} / \mathrm{l}$ arasında değiştiği rapor edilmiştir (EkerDeveli vd., 2003). Yılmaz vd. (2006) İstanbul 
Boğazı ile Kuzeybatı kıta sahanlığ arasındaki bölge için 2001 yılı için yüzey suyu klorofil- $a$ değerlerini $\quad 0,03-1,92 \mu \mathrm{g} / 1$ arasinda rapor etmektedirler. Ediger vd. (2006) Güneybatı Karadeniz için ortalama klorofil- $a$ konsantrasyonun $\quad 0,15-1,23 \quad \mu \mathrm{g} / 1$ arasında değiştiğini rapor etmiştir. Ağırbaş (2010) tarafindan Güneydoğu Karadeniz'de aylık dönemler halinde yürütülen çalışmada ise yüzey suyu klorofil- $a$ değerleri kıyı (2 mil) açık (8 mil) için ortalama klorofil-a değerlerini sirasıyla $1,97 \mu \mathrm{g} / 1$ ve $1,84 \mu \mathrm{g} / \mathrm{l}$ bildirmiştir. Koca (2014) Güney Doğu Karadeniz Rize sahillerinde yürüttüğü çalışmasında klorofil- $a$ konsantrasyonunu 0,34-2,71 $\mu \mathrm{g} / \mathrm{l}$ arasinda ve ortalama $1,62 \mu \mathrm{g} / 1$ olarak rapor etmiştir. Daha geniş bir alanda ve farklı karakterlerdeki su kütlelerinde gerçekleştirilen bu çalışmada ise yüzey suyu ortalama klorofil-a konsantrasyonları 2, 8 ve 15 mil için sırasıyla 0,37-2,68 $\mu \mathrm{g} / 1,0,16$ $2,04 \mu \mathrm{g} / 1$ ve $0,32-1,79 \mu \mathrm{g} / 1$ arasında değişim göstermiştir. Ortalama değerler ise sırasıyla $1,22 \mu \mathrm{g} / 1, \quad 0,81 \mu \mathrm{g} / \mathrm{l}$ ve $0,76 \mu \mathrm{g} / 1$ olarak hesaplanmıştır. Elde edilen bu değerler yukarıda sunulan literatür verileriyle kısmen uyumluluk göstermekle beraber nispeten düşük olduğu görülmektedir. Gözlenen bu farklılıklar temelde kullanılan yöntemin farklı olmas1 (HPLC, spektrofotometre, florometre, in-situ floresan ve uzaktan algılama vb), farklı bölgelerde çalışılmış olması (daha geniş bir alan ve açık istasyonlar var olması, nehir ağızları, siklonik ve antisiklonik döngüler vb), çalışma dönemlerinin farklı olması, yürütülen çalışmaların örnekleme periyotlarının sıklığ 1 veya az oluşundan ve fitoplankton komünite yapsındaki değişimlerden kaynaklanabileceği düşünülmektedir.

Karadeniz'de klorofil- $a$ haricinde fotosentetik pigmentler üzerine gerçekleştirilen çalışmaların sayısı oldukça azdır. Bu anlamda yapılan çalışmalar irdelendiğinde; Ediger vd. (2006) tarafından Güneybatı Karadeniz'de tek dönemde gerçekleştirilen çalışmada klorofila'nın yanı sira temel fotosentetik pigmentlerden peridinin, fukoksantin ve 19'Heksanoloksifukoksantin'i HPLC tekniği ile analiz etmiş ve konsantrasyonalarının sirasiyla $0,03-0,33 \mu \mathrm{g} / 1 ; 0,02-0,18 \mu \mathrm{g} / 1$ ve 0,04-0,19 $\mu \mathrm{g} / 1$ arasında değiştiğini rapor etmişlerdir. Güneydoğu Karadeniz'de 2 ve 8 deniz mili mesafesinde yer alan istasyonlarda aylık dönemler halinde yürütülen başka bir çalışmada ise peridinin, fukoksantin ve 19'-Heksanoloksifukoksantin konsantrasyonlarının sirasiyla $0,04-0,45 \mu \mathrm{g} / \mathrm{l}$; $0,06-1,45 \mu \mathrm{g} / 1$ ve $0,04-0,43 \mu \mathrm{g} / 1$ arasinda değişim gösterdiği rapor edilmiştir (Ağırbaş, 2010). Koca (2014) tarafından Güneydoğu Karadeniz Rize sahillerinde yüzey suyunda yürütülen başka çalışmada ise önceki çalışmalardan farklı olarak 4 farklı marker pigment (diadinoksantin, zeaksantin, klorofil$b$ ve $\beta$-Karoten) daha incelenmiş ve bunların aylık değişimleri ortaya konulmuştur (Tablo $1)$.

Tablo 1. Karadeniz'de belirteç pigmentler ( $\mu \mathrm{g} / \mathrm{l})$ üzerine yürütülen çalışmaların karşılaştırılması

Table 1. Comparison of the studies on marker pigments $(\mu \mathrm{g} / \mathrm{l})$ in the Black Sea

\begin{tabular}{|c|c|c|c|c|c|c|c|c|}
\hline Bölge & Perid & Fuko & 19-Heks & Diad & Zea & Klorofil-b & B-Kar & Kaynak \\
\hline $\begin{array}{l}\text { Güneybat1 } \\
\text { Karadeniz }\end{array}$ & $0,03-0,33$ & $0,02-0,18$ & $0,04-0,19$ & - & - & - & - & Ediger vd., 2006 \\
\hline $\begin{array}{l}\text { Güneydoğu } \\
\text { Karadeniz }\end{array}$ & $0,04-0,45$ & $0,06-1,45$ & $0,04-0,43$ & $0,01-1,00$ & $0,01-0,77$ & - & $0,01-0,25$ & Ağırbaş, 2010 \\
\hline $\begin{array}{l}\text { Güneydoğu } \\
\text { Karadeniz }\end{array}$ & $0,04-0,78$ & $0,07-0,90$ & $0,03-0,57$ & $0,01-0,61$ & $0,02-0,47$ & $0,02-0,36$ & $0,01-0,21$ & Koca, 2014 \\
\hline $\begin{array}{l}\text { Güneydoğu } \\
\text { Karadeniz }\end{array}$ & $0,14-3,48$ & $0,02-2,52$ & $0,02-2,56$ & - & $0,03-0,99$ & $0,01-1,67$ & - & $\mathrm{Bu}$ çalışma \\
\hline
\end{tabular}


$\mathrm{Bu}$ çalışmada ise yukarıda adı geçen fotosentetik pigmentlere ilaveten 19Butanoloksifukoksantin ve Alloksantin pigmentleri de analiz edilmiş ve bunlar uygun eşitlikler yardımıyla fitoplankton boy gruplarının \% katkı oranlarının belirlenmesinde kullanılmıştır

$\mathrm{Bu}$ çalışmadan elde edilen marker pigment konsantrasyonları önceki çalışmalarla kıyaslandığında yüksek olduğu dikkat çekmektedir. Yüksek konsantrasyonların okunduğu istasyonlar genellikle kıyıya yakın mesafede ve nehir deşarjı etkisi altına olan istasyonlar (Kemalpaşa, Pazar ve Çamburnu) olup ve genellikle 10 ila $20 \mathrm{~m}$ arasinda kaydedilmiştir.

Pigment konsantrasyonlarına göre hesaplanan fitoplankton boy grupları ve bunların oranları alansal ve zamansal olarak önemli ölçüde değişmiştir. Kasım 2014 döneminde mikroplankton baskınlığı dikkat çekerken bunu nano- ve pikoplankton takip etmiştir. $\mathrm{Bu}$ durum pigment konsantrasyonlarında da kendini göstermiştir. Bu dönemde özellikle peridinin ve fukoksantin konsantrasyonu oldukça yüksek çıkmıştır (sırasıyla 3,48 $\mu \mathrm{g} / \mathrm{l}$ $2,52 \mu \mathrm{g} / \mathrm{l})$. Su kolonunun daha homojen olduğu Şubat 2015 döneminde ise mikroplankton baskınlığı dikkat çekmiştir. $\mathrm{Bu}$ dönemde nanoplankton gruplarının katkısı özellikle 20 m'lerden sonra önemli ölçüde artış göstermiştir. $\mathrm{Bu}$ derinlikler klorofil maksimumun (10-20 m) altına denk gelmektedir. $\mathrm{Bu}$ dönemde pikoplanktonun katkıs1 az kalırken bazı istasyonlarda (Kemalpaşa 2 ve 8 mil) klorofil maksimuma denk gelen derinliklerde oranlarında \%40'a kadar artış görülmüştür. Mayıs 2015 döneminde yeni besin tuzu girdisine bağlı olarak mikroplankton tekrar artış sergilemiş ve \%85 seviyelerine kadar ulaşmıştır. Diğer taraftan nanoplankton katkısı azalırken pikoplanktonun katkısı özellikle yüzey sularında artmıştır. $\mathrm{Bu}$ dönemde klorofil maksimum daha derinlere inmiş ve kıyı sularda 30 m'de tespit edilmişken açık sularda 40 m'de tespit edilmiştir. Özellikle pikoplankton klorofil maksimuma denk gelen derinliklerde en yüksek katk1 oranına ulaşmıştır. Termoklinin tabakasının çok güçlü olduğu ve nütrientlerin tüketildiği Ağustos 2015 döneminde yüzey sularında pikoplankton katkısı önemli oranda artış göstermiştir. Katkısı \%40-80 arasında olan mikroplanktonun katkıs1 termoklin tabakasının başladığı derinliğe kadar $(20 \mathrm{~m})$ azalmış ve termoklin tabakasından sonra tekrar artış göstermiştir. $\mathrm{Bu}$ dönemde nanoplanktonun katkısı önemli ölçüde (\%20) azalmıştır.

Barlow vd. (2002) mikroplankton ve nanoplanktonun baskın olduğu ötrofik karakterdeki suların pigment kompozisyonun da homojen olduğu ve bunların su kolonu içerisindeki dağılımlarının derinlikle beraber azaldığını rapor etmişlerdir. Benzer bir durum özellikle mikroplanktonik gruplarda Kasım 2014 ve Şubat 2015 dönemlerinde gözlenmiştir (Şekil 8). Saha çalışmaları oligotrofik bölgelerde fitoplankton komünite yapısının pikoplankton tarafindan domine edildiği ve klorofil maksimuma doğru inildikçe nanoplankton katkısının arttığını göstermiştir (Gibb vd., 2000; Barlow vd., 2002). Nanoplanktonun klorofil maksimum ve altında neden bu denli yüksek olduğunun nedenleri tam olarak ortaya konulamazken bununla ilgili birkaç teori ortaya atılmıştır. Claustre ve Marty (1995) nanoplaktonun nütrikline yakın bölgelerde gelişebildiğinin ve düşük 1şık şartlarının nitrat alımını etkilediğini ve dolayısıyla bu derinliklerde bu grup üyelerinin yüksek oranlarda olduğunu rapor etmiştir. Diğer taraftan Perez vd. (2006) klorofil maksimumdaki nanoplankton baskınlığını nütriklindeki yüksek in-situ büyüme oranına, düşük 1şık koşullarına karşı geliştirilen fizyolojik adaptasyon, yüksek nütrient konsantantrasyonu, fitoplanktonik grupların agregasyon davranışları ve fitoplankton üzerindeki grazing baskıs1 şeklinde açıklamışlardır. Çalışmanın 
yürütüldüğü dönemde özellikle Şubat 2015 döneminde klorofil maksimumun (10-20 m) dan itibaren önemli ölçüde nanoplankton baskınlığı dikkat çekmektedir. $\mathrm{Bu}$ durum diğer mevsimlerde görülmesine rağmen bu dönemdeki gibi bariz değildir. Öte yandan sistemin besin tuzları açısından oligotrofikliğe kaydığı ve mevsimsel termoklin tabakasının çok bariz bir şekilde ortaya çıktı̆̆ A Ăustos 2015 döneminde yüzey sularda pikoplanktonun katkısı dikkat çekmektedir. Fitoplankton boy gruplarında gözlemlenen bu durum yukarıda bahsedilen mekanizmalarla da örtüşmektedir. Benzer şekilde nehir girdisi ve yağışlara bağlı olarak fotik bölgeye yeni nütrient girdisinin olduğu ilkbahar döneminde, termoklin tabakasının kaybolmaya başladığı sonbahar dönemi ve sonraki dönemlerde bölgede mikroplankton önemli oranda katk1 yapan grup olurken bunu nanoplankton takip etmiştir.

Sonuç olarak pigmente dayalı fitoplankton gruplarının tahmin edilmesi ve toplam fitoplanktona yaptığı katkı oranlarının tespit edilerek HPLC tekniği ile kısa sürede ortaya konulması ve özellikle geniş çalışma bölgeleri hakkında başarılı sonuçlar verdiği bu çalışma ile ortaya konulmuştur. Ancak sadece marker pigmentleri kullanarak bu karakterizasyonu yapmak yanıltıcı olabilir (Gieskes, 1991; Millie vd., 1993; Brewin vd., 2010; Ağırbaş vd., 2015). Pigmente dayalı yapilan tahminler fitoplankton grup oranları hakkında bilgi verirken sistematik açıdan (tür teşhisi vb.) net bir bilgi ortaya koyamamaktadır. Bundan dolayı HPLC tekniğinin mikroskobik hücre sayımları ile desteklenmesi büyük önem arz etmektedir.

\section{Teşekkür}

Bu çalışma TÜBİTAK 113Y189 nolu proje ile desteklenmiştir. Deniz çalışmaları esnasında yardımlarından dolayı proje ekibine, " $\mathrm{R} / \mathrm{V}$ SÜRAT ARAŞTIRMA I" gemisi kaptan ve gemi adamlarına teşekkür ederiz.

${ }^{[*} \mathrm{Bu}$ Çalışma Recep Tayyip Erdoğan
Üniversitesi Fen Bilimleri Enstitüsü $\mathrm{Su}$ Ürünleri Anabilim Dalı'nda yüksek lisans tez çalışması olarak sunulan "Güneydoğu Karadeniz Kıyıları (Artvin-Giresun) Pigment Kompozisyonun Mevsimsel Değişimi” isimli tezden üretilmiştir.

\section{Kaynaklar}

Ağırbaş, E. (2010). Güneydoğu Karadeniz'de Pigment Konsantrasyonu ve Birincil Üretimin Çevre Koşulları ile Etkileşimi, (Doktora Tezi) Karadeniz Teknik Üniversitesi, Fen Bilimleri Enstitüsü Trabzon, Türkiye, 199s.

Ağırbaş, E., Martinez-Vicente, V., Brewin, RJW., Racault, MF., Airs, RL., Llewellyn, CA. (2015). Temporal changes in total and size-fractioned chlorophyll-a in surface waters of three provinces in the Atlantic Ocean (September to November) between 2003 and 2010. Journal of Marine Systems, 150, 56-65.

Aiken, J., Pradhan, Y., Barlow, R., Lavender, S., Poulton, A., Holligan, P., Hardman-Mountford N. (2009). Phytoplankton pigments and functional types in the Atlantic Ocean: A decadal assessment, 1995-2005. Deep-Sea Research Part II-Topical Studies in Oceanography, 56 (15), 899-917.

Barlow, R.G., Aiken, J., Moore, G.F., Holligan, P.M., Lavender, S. (2004). Pigment adaptations in surface phytoplankton along the eastern boundary of the Atlantic Ocean. Marine Ecology Progress Series, 281, 13-26.

Barlow, R.G., Aiken, J., Holligan, P.M., Cummings, D.G., Maritorena, S., Hooker, S. (2002). Phytoplankton pigment and absorption characteristics along meridional transects in the Atlantic Ocean. Deep-Sea Research Part IOceanographic Research Papers, 49 (4), 637660.

Brewin, R.J.W., Sathyendranath, S., Hirata, T., Lavender, S.J., Barciela, R.M., HardmanMountford, N.J. (2010). A three-component model of phytoplankton size class for the Atlantic Ocean. Ecological Modelling, 221 (11), 1472-1483.

Boyce, D.G., Lewis, M.R., Worm, B. (2010). Global phytoplankton decline over the past century. Nature, 466 (7306), 591-596.

Claustre, H., Marty, J.C. (1995). Specific phytoplankton biomasses and their relation to primary production in the tropical North Atlantic. Deep-Sea Res Part I, 42, 1475-1493.

Ediger, D., Weeks, A. R., Robinson, S. I., Sagan, S. 
(2001). Pigment Signatures Reveal Temporal Regional Differences in Taxonomic Phytoplankton Composition off the West Coast of Ireland, Journal of Plankton Research, 23, 893-902.

Ediger, D., Soydemir, N., Kideys, A.E. (2006). Estimation of phytoplankton biomass using HPLC pigment analysis in the Southwestern Black Sea. Deep Sea Research, 53, 1911-1922.

Eker-Develi, E., Kideys, A.E. (2003). Distribution of phytoplankton in the southern Black Sea in summer 1996, spring and autumn1998. Journal of Marine Systems, 39, 203-211.

Eker-Develi, E., Berthon, J.F., Linde, D. (2008). Phytoplankton class determination by microscopic and HPLC-CHEMTAX analyses in the southern Baltic Sea. Marine Ecology Progress Series, 359, 69-87.

Eker-Develi, E., Berthon, J.F., Canuti, E., Slabakova, N., Moncheva, S., Shtereva, G., Dzhurova, B. (2012) Phytoplankton taxonomy based on CHEMTAX and microscopy in the Northwestern Black Sea. Journal of Marine Systems, 94,18-32.

Falkowski, P. G., Raven, J. A. (2007). Aquatic photosynthesis, Princeton University Press, Second edition, $484 \mathrm{~s}$.

Gibb, S.W., Barlow, R.G., Cummings, D.G., Rees, N.W., Trees, C.C., Holligan, P., Suggett, D. (2000). Surface phytoplankton pigment distributions in the Atlantic Ocean: an assessment of basin scale variability between $50^{\circ} \mathrm{N}$ and $50^{\circ} \mathrm{S}$. Progress in Oceanography, 45, 339-368.

Gibb, SW, Cummings, D.G., Irigoien, X., Barlow, R.G., Fauzi, R, Mantoura, C. (2001). Phytoplankton pigment chemotaxonomy of the northeastern Atlantic, Deep Sea Research II, 48, 795-823.

Gieskes, W. W. C., Kraay, G. W. (1983). Dominance of Cryptophyceae during the Phytoplankton Spring Bloom in the Central North Sea Detected by HPLC Analysis of pigments, Marine Biology, 75, 179-185.

Gieskes, W.W.C. (1991). Algal pigment fingerprints: clue to taxonspecific abundance, productivity and degradation of phytoplankton in seas and oceans. In: Demers, S. (Ed.), Particle Analysis in Oceanography, NATO ASI Series', vol. G27. pp. 61-69.

Jeffrey, S.W., Vesk, M. (1997). Introduction to marine phytoplankton and their pigment signatures. In: Jeffrey SW, Mantoura RFC, Wright SW (Eds.), Phytoplankton Pigments in Oceanography: Guidelines to Modern Methods.
UNESCO, Paris, pp. 19-36.

Koca, L. (2014). Güney Doğu Karadeniz Kıyıları (Rize) Diatom/Dinoflagellat Oranları ve Pigment Kompozisyonun Zamansal Değişimi, Yüksek Lisans Tezi, Recep Tayyip Erdoğan Üniversitesi, Fen Bilimleri Enstitüsü, $73 \mathrm{~s}$.

Mackas, D.L. (2011). Does blending of chlorophyll data bias temporal trend Nature, 472 (7342), E4E5.

Millie, D. F., Paerl, H.W., Hurley, J.P. (1993). Microalgal Pigment Assessments Using High Performance Liquid Choramotography: a Synopsis of Organismal and Ecological Applications, Canadian Journal of Fisheries an Aquatic Sciences, 50, 2513-2527.

Nair, A., Sathyendranath, S., Platt, T., Morales, J., Stuart, V., Forge, M.H., Devred, E., Bouman, H. (2008). Remote sensing of phytoplankton functional types. Remote Sensing of Environment, 112 (8), 3366-3375.

Obayashi, Y., Tanoue, E., Suzuki, K., Handa, N., Nojiri, Y., Wong, C. S. (2001). Spatial and Temporal Variabilities of Phytoplankton Community Structure in the Northern North Pacific as Determined by Phytoplankton Pigments, Deep-Sea Research I, 48, 439-469.

Perez, V., Fernandez, E., Maranon, E., Serret,P., Varela, R., Bode, A., Varela, M.,Varela, M.M., Moran, X., Woodward, E.M.S., Kitidis, V., Garcia-Soto, C. (2005). Latitudinal distribution of microbial plankton abundance, production, and respiration in the Equatorial Atlantic in Autumn 2000. Deep-Sea Research I, 52, 861880.

Takahashi, T., Sutherland, S.C., Sweeney, C., Poisson, A., Metzl, N., Tilbrook, B., Bates, N., Wanninkhof, R., Feely, R.A., Sabine, C., Olafsson, J., Nojiri, Y. (2002). Global sea-air $\mathrm{CO}_{2}$ flux based on climatological surface ocean $\mathrm{pCO}_{2}$, and seasonal biological and temperature effects. Deep-Sea Research Part II-Topical Studies in Oceanography, 49 (9-10), 16011622.

Trees, C. C., Clark, D. K., Bidigare, R.R., Ondrusek, M. E., Mueller, J. L. (2000). Accessory Pigments Versus Chlorophyll-a Concentrations within Euphotic Zone: a Ubiquitous Relationships, Limnology and Oceanography, 45 (5), 1130-1143.

Uitz, J., Claustre, H., Morel, A., Hooker, S.B. (2006). Vertical distribution of phytoplankton communities in open ocean: An assessment based on surface chlorophyll. Journal of Geophysical Research-Oceans, C003207.

Vidussi, F., Claustre, H., Manca, B.B., Luchetta, 
A., Marty, J.C. (2001). Phytoplankton pigment distribution in relation to upper thermocline circulation in the Eastern Mediterranean Sea during winter. Journal of Geophysical Research, 106 (19), 19939-19956.

Wright, S. W., Shearer, J. D. (1984). Rapid Extraction and High-Performance Liquid Chromatography of Chlorophyll-a and carotenoids from Marine Phytoplankton, Journal of Chromatography, 29, 281-294.

Wright, S.W., Jeffrey, S.W. (1987). Fucoxanthin pigment markers of marine phytoplankton analysed by HPLC and HPTLC. Marine Ecology Progress Series, 38, 259-266.

Wright, S. W., Thomas, D. P., Marchant, H. J., Higgins, H. W., Mackey, M. D., Mackey, D. J. (1996). Analysis of Phytoplankton of the Australian Sector of the Southern Ocean: Composition of Microscopy and Size Frequency Data with Interpretations of Pigment HPLC Data Using the CHEMTAX Matrix Factorization Program, Marine Ecology Progress Series, 144, 285-298.

Y1lmaz, A., Tugrul, S., Polat, C., Ediger, D.,
Çoban, Y., Morkoc, E. (1998). On the Production, Elemental Composition (C, N, P) and Distribution of Photosynthetic Organic Matter in the Southern Black Sea, Hydrobiologia, 363, 141-156.

Yunev, O., Vladimir, A., Baştürk, Ö., Yılmaz, A., Kideyş, A. E., Moncheva, S., Konovalov, S. K. (2002). Long-term Variation of Surface Chlorophyll-a and Primary Production in the open Black Sea, Marine Ecology Progress Series, 230, 11-28.

Yücel, N., Uysal, Z. (2017). Kuzeydoğu Akdeniz'de Kıyısal ve Açık sularda Fitoplankton Dinamikleri, Yunus Araştırma Bülteni, 17(1), 29-40.

Yücel, N., Uysal, Z., Tuğrul, S. (2017). Variability in phytoplankton pigment composition in Mersin Bay, Turkish Journal of Aquatic Sciences, 32(1), 49-70.

Yücel, N. (2017). Fitoplankton sınıflarının belirlenmesinde HPLC ve spektroflorometrik yöntemlerin karşılaştırılması, Yunus Araştırma Bülteni, 17(2), 163-170. 